\title{
GESTÃO TERRITORIAL DO SISTEMA DE PARQUES PÚBLICOS EM SALVA- DOR, BAHIA: CONTRADIÇÕES E PARADOXOS
}

\author{
Contradictions and paradoxes on territorial management of public parks system \\ in Salvador, Bahia
}

\author{
Angelo SERPA ${ }^{1}$
}

\section{RESUMO}

Busca-se, neste artigo, elucidar as estratégias e os instrumentos de gestão municipal do sistema de parques públicos em Salvador-Bahia, a partir da análise do Plano Diretor de Desenvolvimento Urbano e Ambiental, apontando para possíveis contradições e paradoxos entre as políticas recentes de requalificação urbana e as diretrizes e determinações contidas no PDDUA. São analisados a distribuição espacial da cobertura vegetal e seu "valor ecológico" no território municipal e a classificação das unidades de conservação no município, bem como as políticas de requalificação urbana empreendidas pelas gestões municipais ao longo das duas últimas décadas. A análise dos exemplos ao longo do artigo mostra que, embora os parques públicos sejam abordados tanto sob a ótica ambiental como sob a ótica do lazer no Plano Diretor, prevalece a última lógica como diretriz das políticas de requalificação urbana desses equipamentos nos limites do município. Ao final do artigo, enfatiza-se a centralidade da questão da acessibilidade - física e simbólica - e da distribuição espacial dos espaços públicos de natureza para uma discussão acadêmica profunda, que possa fundamentar em outras bases a gestão dos parques públicos no território municipal, a partir de uma análise crítica das idéias de desenvolvimento sustentável e sustentabilidade.

\section{Palavras-chave:}

Gestão territorial; sistema de parques públicos; sustentabilidade; Salvador-Bahia

\begin{abstract}
This article aims at making public parks system municipal strategies and management instruments clear in Salvador, state of Bahia/Brazil, from the analysis of the city Directing Plan of Urban and Environment Development (PDDUA), pointing out the possible contradiction and paradox between the late politics of urban re-qualification and the PDDUA determinations and directives. It analyses the spatial vegetal cover distribution and its "ecologic value" in the municipal territory and the classification of conservation unities in the city as well as the urban re-qualification politics undertaken by the municipal administrations in the two last decades. The analyses of the presented examples show that, in despite of the Directing Plan's approach of public parks both on environmental way than in the recreation one.The last way as the directive of urban re-qualification politics of these spaces in the city prevails. At the end of the article, it is emphasized the central importance of the physical and symbolic access question and of the spatial distribution of nature public spaces for one deep academic discussion looking for other basis for the municipal territory public parks management from one critical analyses of the ideas of sustainable development and sustainability.
\end{abstract}

\section{Key-words:}

Territorial management; Public parks system; Sustainability; Salvador; Bahia.

\footnotetext{
${ }^{1}$ Professor adjunto do Departamento de Geografia da Universidade Federal da Bahia. Pesquisador do CNPq. E-mail: angserpa@ufba.br
} 


\section{INTRODUÇÃO}

Pretende-se, neste artigo, discutir a gestão territorial de Salvador, a partir da análise de um aspecto específico: a gestão do sistema de parques públicos no município soteropolitano. Busca-se elucidar as estratégias e os instrumentos de gestão municipal dos parques públicos, a partir da análise do Plano Diretor de Desenvolvimento Urbano e Ambiental - atualmente em processo de revisão -, apontando para possíveis contradições e paradoxos entre as políticas recentes de requalificação urbana e as diretrizes e determinações contidas no PDDUA, aprovado pela Câmara Municipal em agosto de 2004, por meio da Lei $n^{\circ} 6.586 / 2004$.

O PDDUA é o instrumento básico da política de desenvolvimento e expansão urbana do município para o período de oito anos. A partir de 15 de junho de 2005, o PDDUA passou a ser rediscutido nas regiões administrativas da cidade, em processo conduzido pela Câmara e pela Prefeitura Municipal. Não se trata aqui de discutir a qualidade da participação da população no processo de elaboração e revisão do Plano Diretor, motivo de muitas polêmicas e da atuação decisiva do Ministério Público, no intuito de garantir a participação popular no processo de elaboração e revisão do referido documento ${ }^{2}$. Trata-se, antes de tudo, de examinar a lógica das diretrizes e determinações do plano no tocante ao sistema de parques públicos no território municipal.

Os parques públicos são abordados no PDDUA sob dois aspectos: pela ótica ambiental, vistos como "espaços verdes" e de conservação, e pela ótica do lazer, vistos enquanto espaços públicos voltados para a recreação e o entretenimento. Sob a ótica ambiental, os parques compõem um sistema de espaços de preservação ambiental subdividido em dois subsistemas: o das áreas de conservação, cuja importância deve-se ao seu valor ecológico ou à sua significância para a qualidade urbano-ambiental, caracterizadas pelos Parques de $\mathrm{Na}-$ tureza (exemplos: São Bartolomeu e Abaeté) e pelos Parques Urbanos (exemplos: Zoobotânico, da Cidade e Pituaçu); e o das áreas de valor urbano-ambiental, do qual fazem parte os Parques de Recreação (Dique do Tororó, Jardim dos Namorados, Costa Azul e Aeroclube) e os Espaços Abertos Urbanizados (praças, mirantes, jardins públicos, áreas verdes integrantes de loteamentos, campos e quadras poliesportivas).

\section{A DISTRIBUIÇÃO ESPACIAL DA COBERTURA VE- GETAL E SEU “VALOR ECOLÓGICO” NO TERRITÓ- RIO MUNICIPAL: OS PARÂMETROS ESTABELECI- DOS PELO PDDUA}

O relatório final que fundamenta o Plano Diretor de Salvador indica, no tocante à distribuição espacial da cobertura vegetal no município de Salvador, a presença de três macrocompartimentos com configurações distintas, cuja relevância deveria determinar políticas diferenciadas para conservação e recuperação dos padrões observados:

Compartimento Sul - corresponde à porção sul do município, associada à mancha urbana mais antiga da cidade, incluindo as RAs 1, 5, 6, 7 e 8, onde a maior parte da cobertura vegetal está associada a tipologias antrópicas, intensamente modificadas pelo processo de urbanização, constituindo-se manchas isoladas completamente ilhadas em meio ao tecido urbano, com suas funções ecológicas comprometidas.

(...) Como elementos pontuais notáveis do ponto de vista paisagístico, destacam-se as áreas verdes do Farol da Barra, Cristo, Morro do Gavaza, encosta da Vitória, áreas do Campus da UFBA em Ondina, além de áreas públicas mais expressivas como o Jardim Zoobotânico e Parque da Cidade Joventino Silva. Compartimento Leste - corresponde a uma faixa de aproximadamente 20 quilômetros, com largura média de 3 quilômetros ao longo da Av. Paralela e BA-526 (ClA-Aeroporto), onde ocorrem as tipologias de cobertura vegetal mais expressivas do município, não somente em função da presença de remanescentes de mata atlântica em estágios de recuperação avançados e médios, como pela sua continuidade. Constituindo-se num extenso corredor de vegetação e fauna, responsável pela boa qualidade das bacias hidrográficas na porção norte da cidade, com os seus respectivos mananciais de abastecimento.

Destacam-se, como elementos pontuais nesse compartimento, as seguintes manchas de cobertura vegetal:

(...) áreas do Parque Metropolitano de Pituaçu, onde estão presentes aproximadamente 373 ha de florestas ombrófilas em estágios iniciais e médios de recuperação, que já estão sendo conservadas adequadamente pelo poder público, não oferecendo maiores riscos;

(...) restingas nos limites e imediações da APA das Lagoas de Abaeté, correspondentes ao principal remanescente de ecossistemas de restingas em dunas do município, em diversos estágios de regeneração,

2 Cinco audiências públicas serão realizadas em outubro de 2006 para discutir o PDDUA de Salvador. O objetivo dos debates é possibilitar maior participação da população nas definições sobre os rumos da cidade. A expectativa é que, até o final de 2006 , o plano seja encaminhado para aprovação na Câmara dos Vereadores (CORREIO DA BAHIA, 1/10/2006). 
perfazendo uma mancha contínua de aproximadamente 690 ha de relevante importância ecológica, grandemente protegida pela APA do Abaeté, constituindo-se uma área onde não deverão ser permitidos parcelamentos urbanos ou qualquer tipo de atividade que promova a descaracterização de sua cobertura vegetal e modelada;

(...) Compartimento Oeste - Corresponde ao território compreendido entre a orla marítima da Baía de Todos os Santos, e as partes altas das bacias hidrográficas que deságuam no Oceano Atlântico, limitado a leste pelo compartimento leste, constituindo uma miscelânea de restos de vegetação em vertentes íngremes bordejadas por tecido urbano altamente degradado. Destacam-se como elementos relevantes as seguintes manchas individualizadas: (...)áreas de florestas na parte alta da bacia do Pituaçu, nas imediações da Penitenciária Lemos de Brito, entre os bairros de Pau da Lima, Jardim Santo Inácio e Mata Escura, perfazendo um total de aproximadamente 170 ha de florestas em estágios médio e inicial ao longo de áreas de nascentes da bacia do Pituaçu, o que aumenta significativamente a sua importância como elemento mantenedor do equilíbrio hídrico do sistema;

(...)remanescentes florestais da bacia do Cobre associados a florestas ombrófilas em estágios avançados, médios e iniciais, perfazendo um total de 653 ha em área de proteção de manancial de abastecimento (PLANO DIRETOR DE DESENVOLVIMENTO URBANO DE SALVADOR ESTUDOS AMBIENTAIS - RELATÓRIO FINAL, 2004, p. 57-59, grifos nossos).

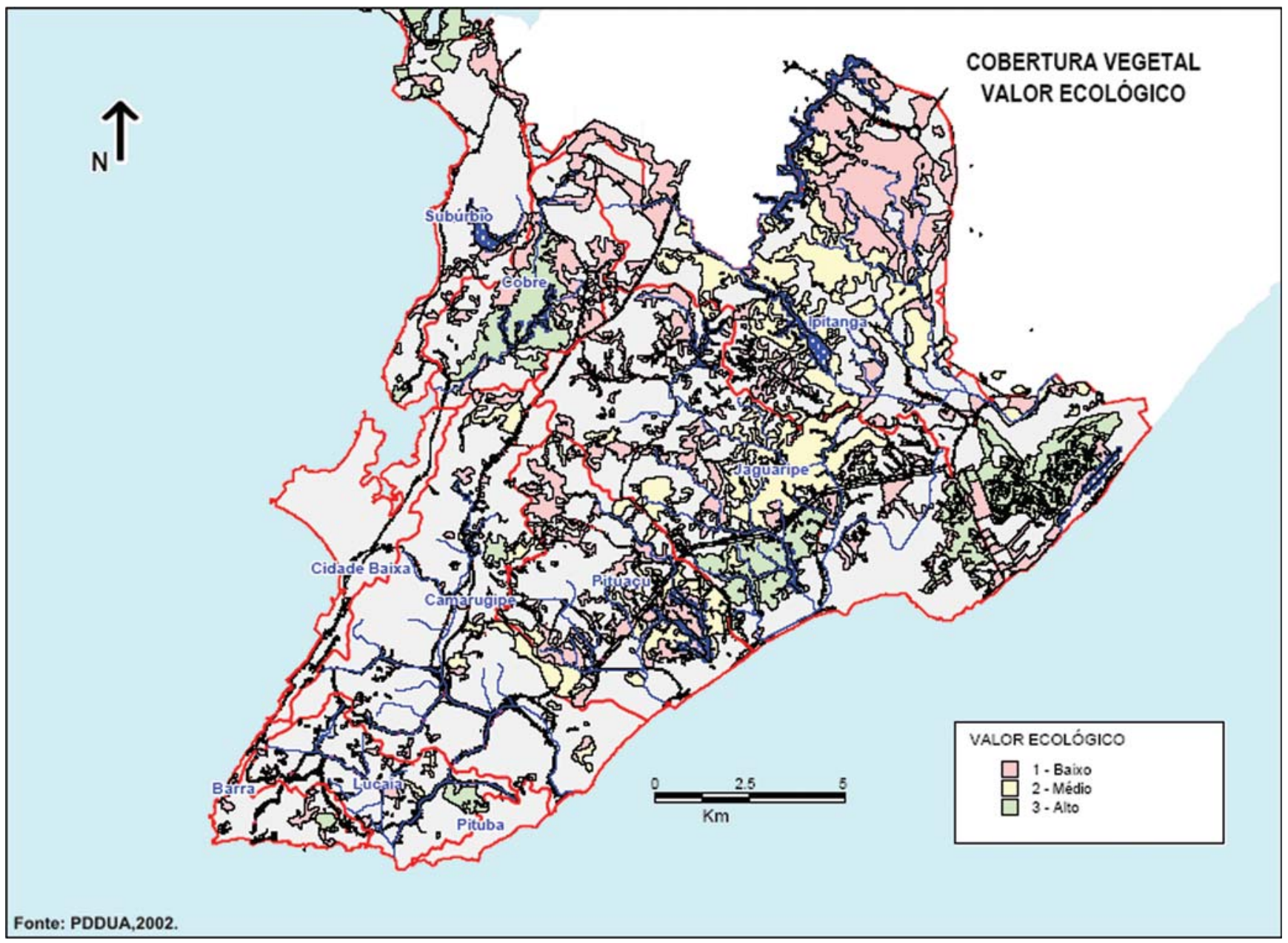

FIGURA 1 - COBERTURA VEGETAL EM SALVADOR, BAHIA: VALOR ECOLÓGICO 
O mesmo relatório analisa também a distribuição espacial das áreas com maior "valor ecológico" 3 no território municipal (Figura 1), identificando três grandes bolsões de cobertura vegetal correspondentes às florestas ombrófilas em estágio de recuperação avançado e/ou às restingas:

- bolsão de vegetação ao norte da represa de Pituaçu, entre a Avenida Paralela e a praia de Patamares;

- $\quad$ restingas na região de Abaeté;

- florestas a montante da represa do Cobre.

Verifica-se que alguns dos parques urbanos e de natureza mencionados no início dessa seção (Pituaçu, Abaeté, São Bartolomeu e da Cidade) aparecem entre as áreas da cidade com médio a alto valor ecológico, o que deveria determinar, como indicado pelo Plano Diretor, políticas públicas de conservação, preservação e recuperação ambiental; no entanto, as políticas de requalificação do espaço público, empreendidas no território municipal a partir dos anos 1990, parecem contradizer essa lógica, como veremos nas próximas seções.

\section{PARQUES E JARDINS PÚBLICOS: ENTRE PALCO E BASTIDOR}

Depois da segunda metade dos anos 1990, a cidade de Salvador empreendeu uma política sistemática de criação e reabilitação de parques e jardins públicos. Não por acaso, esse período coincide com duas impor- tantes mudanças relativas ao conjunto das grandes cidades do mundo e, em particular, daquelas situadas nos países ditos "emergentes", onde esses fenômenos vão ocorrer com mais intensidade.

A primeira corresponde a uma nova ideologia cuja origem situa-se no continente europeu: o conceito de desenvolvimento e da cidade "sustentáveis". Iniciada na Europa, durante a conferência de Aalborg, e retomada em seguida na conferência do Rio de Janeiro em 1994, a reflexão sobre a cidade sustentável nasce a partir de uma releitura crítica do desenvolvimento urbano contemporâneo (EMELIANOFF, 2004). A idéia de "sustentabilidade" percorreu o mundo inteiro, criando de fato uma dinâmica "efervescente" de idéias e experiências.

O princípio de base é relativamente simples: essas políticas de desenvolvimento sustentável dão novos poderes às instâncias locais e permitem a resolução de um certo número de problemas ecológicos e sociais por meio de uma reapropriação da cena política local, de uma nova concepção de "democracia urbana". O princípio se apóia na idéia de que a melhoria da qualidade de vida urbana valoriza a imagem e a atratividade das cidades, as áreas verdes servindo a esse fim. Salvador também se inscreve nesse processo de desenvolvimento sustentável, mas é necessário perguntar se tal política apresenta peculiaridades inerentes ao contexto da capital baiana, constatando-se que a situação socioeconômica da Bahia e do Brasil está longe daquela verificada nos países ricos.

A segunda mudança está relacionada com a evolução socioeconômica do Brasil. Se os anos 1970-1980

\begin{tabular}{|c|c|c|}
\hline Parque & Área (metros quadrados) & Existência de Equipamentos \\
\hline Parque do Abaeté & 2.250 .000 & sim \\
\hline Parque de Pituaçu & 4.500 .000 & sim \\
\hline Parque São Bartolomeu & 750.000 & não \\
\hline Parque da Cidade & 720.000 & sim \\
\hline Dique do Tororó & 110.000 & sim \\
\hline Parque Costa Azul & 55.000 & sim \\
\hline Jardim dos Namorados & 80.000 & sim \\
\hline Parque Zoobotânico & 250.000 & não \\
\hline Parque de Exposições & 300.000 & não \\
\hline Parque Atlântico & 102.600 & sim \\
\hline
\end{tabular}

QUADRO 1 - CARACTERIZAÇÃO DOS PARQUES DE SALVADOR - NOVEMBRO DE 2000

FONTE: ESTUDO DE LAZER - PDDUA SALVADOR, 2002.

${ }^{3}$ Para avaliação do valor ecológico foram utilizados os seguintes indicadores: importância do ecotopo sobre funções particulares do sistema - presença de componentes-chave na manutenção da dinâmica do sistema, concorrendo para a manutenção do seu equilíbrio dinâmico; endemismo e valor biogeográfico - presença de espécies endêmicas, representativas do ambiente em termos da sua biogeografia; representatividade ecológica - presença de ecossistemas importantes com representatividade geográfica, considerando-se a totalidade do sistema objeto da análise; raridade/unicidade - presença de espécies raras e de sistemas raros, considerando-se áreas adjacentes e de influência direta; naturalidade - presença de ambientes onde as tipologias vegetais aproximam-se do estado climático. 
foram marcados pelo aumento do poder (econômico e político) das classes médias, em meados dos anos 1990 assiste-se, nas maiores aglomerações urbanas do país, um aumento expressivo das desigualdades entre ricos e pobres. Essa evolução encontra reflexo na paisagem urbana, que testemunha o surgimento de novos bairros residenciais servidos de centros comerciais e boa infraestrutura urbana, do mesmo tipo que aqueles encontrados nos países mais prósperos.

A conjugação dessas mudanças vai se materializar no espaço urbano por meio da criação e da reabilitação de parques e jardins públicos. De uma maneira mais "confidencial" os efeitos dessas novas políticas podem ser observados também a partir da leitura e análise dos documentos oficiais de urbanismo. Os parques e jardins podem assumir papéis de "cenário" ou "bastidor": de vitrine para alguns, porque próximos de bairros mais "nobres", de bastidor para outros, porque mais dis- tantes das áreas centrais e mais próximos dos bairros de perfil mais popular. A análise dos documentos urbanísticos oficiais indica claramente as diferentes modalidades de parques e jardins públicos na capital baiana, a partir da relação visibilidade/invisibilidade.

\section{A CLASSIFICAÇÃO DAS UNIDADES DE CONSERVA- ÇÃO: ALGUNS PARADOXOS}

A leitura do mapa de áreas protegidas, do Plano Diretor de Desenvolvimento Urbano de Salvador, mostra de modo eloqüente essa nova ideologia de desenvolvimento sustentável (Figura 2). A cidade inventariou de modo sistemático as potencialidades ecológicas do conjunto da aglomeração. O inventário dividiu a cidade em unidades de conservação, com graus distintos de qualidade ecológica da cobertura vegetal.

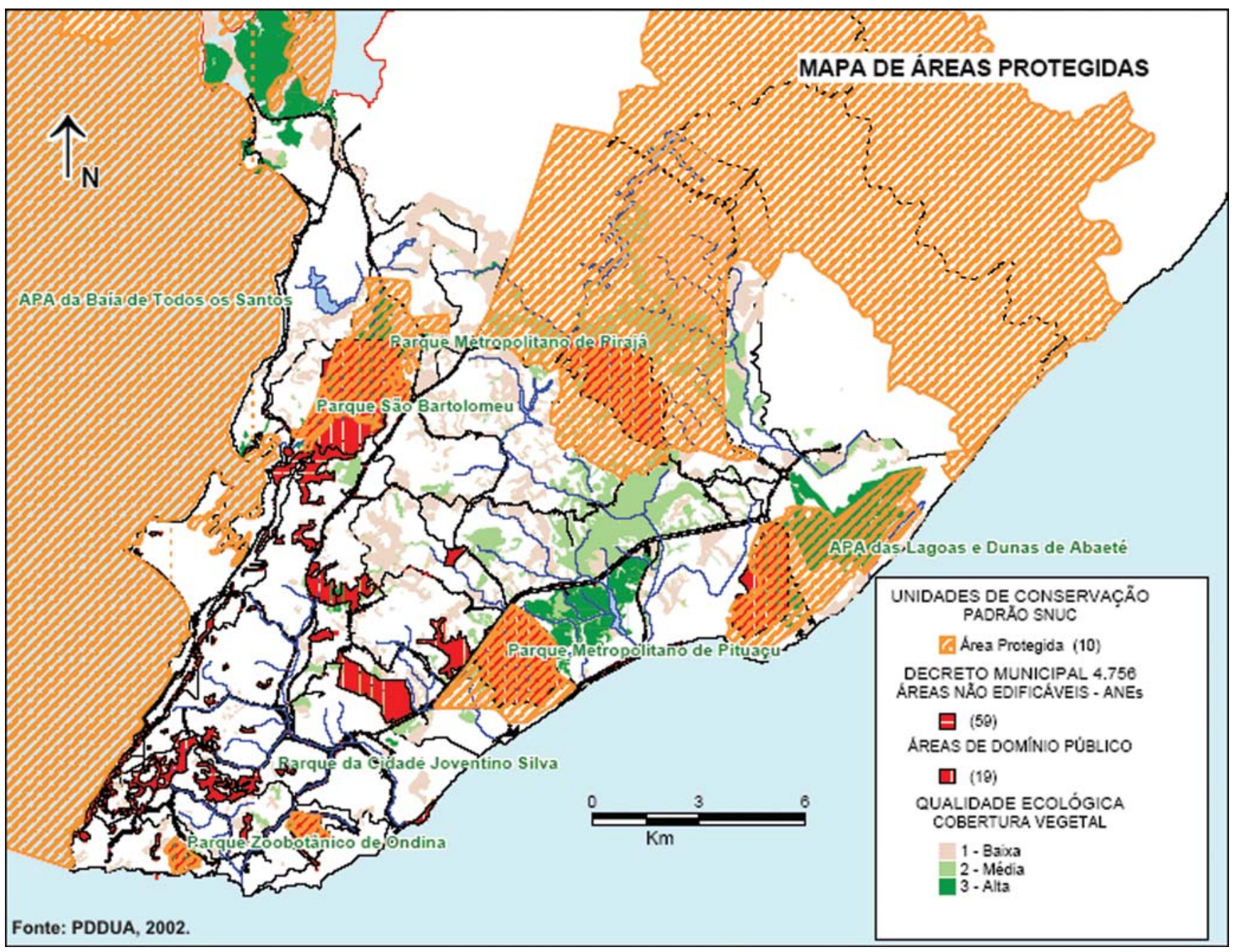

FIGURA 2 - MAPA DE ÁREAS PROTEGIDAS DE SALVADOR - BAHIA 
Constata-se que uma grande parte da aglomeração urbana é composta por áreas protegidas, que ocupam superfícies consideráveis do tecido urbano: é o caso precisamente da Baía de Todos os Santos e de toda a parte norte da cidade, que correspondem também às reservas hídricas necessárias ao abastecimento da aglomeração. A qualidade ecológica da cobertura vegetal não parece constituir, no entanto, um critério determinante para a implantação de áreas protegidas. Isso pode ser constatado, por exemplo, para o Parque de Pituaçu (alta qualidade ecológica da cobertura vegetal existente, mas sem proteção em toda sua extensão). Inversamente, unidades de conservação mais importantes em superfície (Parque Metropolitano de Pirajá e São Bartolomeu) apresentam qualidade ecológica média e são protegidas em toda sua extensão.

Nesse documento aparecem igualmente e freqüentemente superpostas as áreas de domínio público (entre elas, os parques e jardins) e as zonas não edificáveis. Essas zonas aparecem destacadas nas áreas mais densamente povoadas da aglomeração, correspondendo sempre aos parques e jardins públi- cos: essas áreas de domínio público são raramente protegidas, não apresentando, em geral, uma qualidade ecológica digna de nota (como, por exemplo, os Parques Costa Azul, das Esculturas e o Jardim dos Namorados).

Os levantamentos de campo realizados em Salvador em parceria com Francine Deloisy-Barthe, pesquisadora do Laboratório Espace et Cultures (Paris IV), fornecem elementos explicativos indispensáveis a nossa demonstração em termos de visibilidade: em todos os casos, os lugares mais centrais são também "hipervisíveis" na paisagem urbana, enquanto outros, mais distantes dos bairros mais prósperos, permanecem à sombra dos projetos oficiais e não são objeto de qualquer tipo de intervenção. Constata-se um paradoxo em relação à "sustentabilidade urbana", já que a qualidade ecológica não parece constituir-se em critério determinante para as operações de requalificação e o fato de ser "protegido" ou indicado como área de preservação ou conservação ambiental não garante necessariamente sua manutenção, como no caso do Parque Metropolitano de Pirajá/São Bartolomeu.

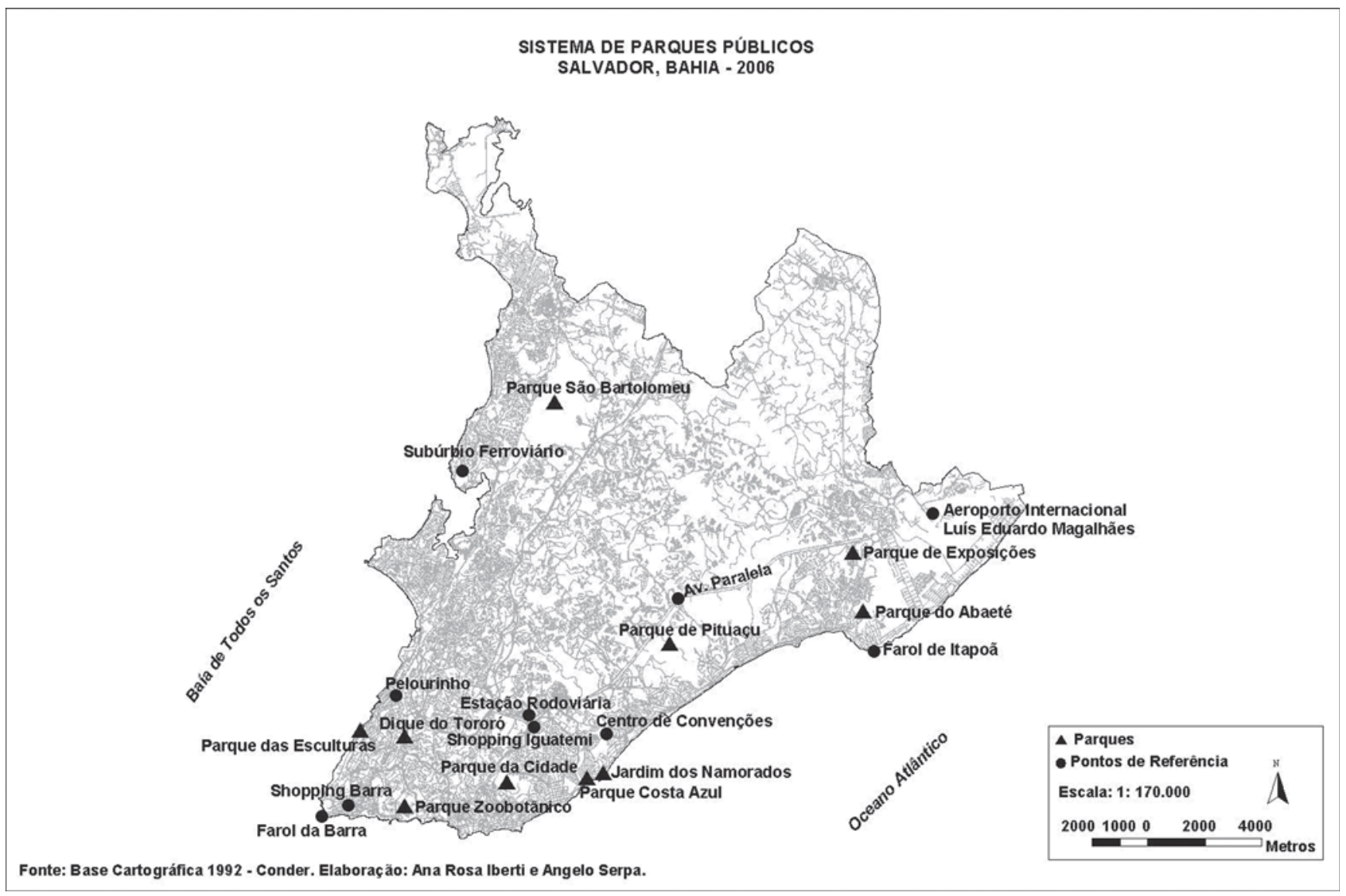

FIGURA 3 - SISTEMA DE PARQUES PÚBLICOS EM SALVADOR - BAHIA 
Enquanto alguns parques são extremamente pobres em cobertura vegetal, não possuindo também nada de excepcional em termos de qualidade estética, e representam um papel significativo na cena urbana, outros, preciosos em termos ecológicos, não recebem qualquer tipo de projeto ou intervenção. Como interpretar essa contradição?

\section{DO PARQUE "VITRINE" AO PARQUE ESQUECIDO OU DE COMO REFORÇAR A SEGREGAÇÃO SOCIO- ESPACIAL}

A correlação entre riqueza e pobreza de certos bairros da cidade e o valor ecológico de certas áreas classificadas como unidades de conservação - são fatores importantes para a compreensão dos processos de segregação socioespacial em Salvador, especialmente se analisarmos os mapas de distribuição da renda dos chefes de domicílio, com foco naqueles de maior (acima de 20 salários mínimos) e de menor poder aquisitivo (até dois salários mínimos), que podem ajudar na tentativa de elucidação desses processos.

Constata-se, em primeiro lugar, que as famílias de baixa renda são majoritárias para o conjunto do município (Figura 4). Elas ocupam a maior parte da superfície da aglomeração, com exceção daquelas áreas litorâneas banhadas pelo Oceano Atlântico, situadas na porção sudeste e norte da península soteropolitana, onde se concentram as camadas da população de maior renda familiar.

O mapa com os responsáveis pelos domicílios mais ricos (Figura 5) mostra uma distribuição concentrada em duas áreas, uma na parte litorânea atlântica sul e sudeste e outra, mais expressiva, em torno do Parque de Pituaçu. A repartição das classes de renda mais alta, incluindo as classes médias, coincide exatamente com a localização dos projetos mais recentes de criação ou requalificação de parques públicos.

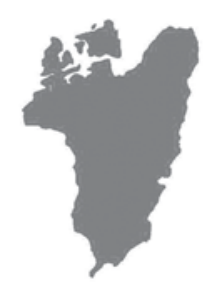

$\square$ Limite do Município de Salvador

Faixas Porcentuais $0,00-18,87$

$18,88-39,55$

$39,56-58,13$

$58,14-73,60$

$73,61-95,77$

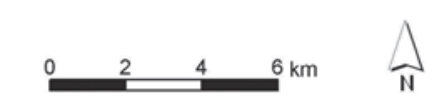

Fonte: CONDER / IBGE, Censo Demográfico, 2000 Base Cartográfica SICAR / RMS, 1992

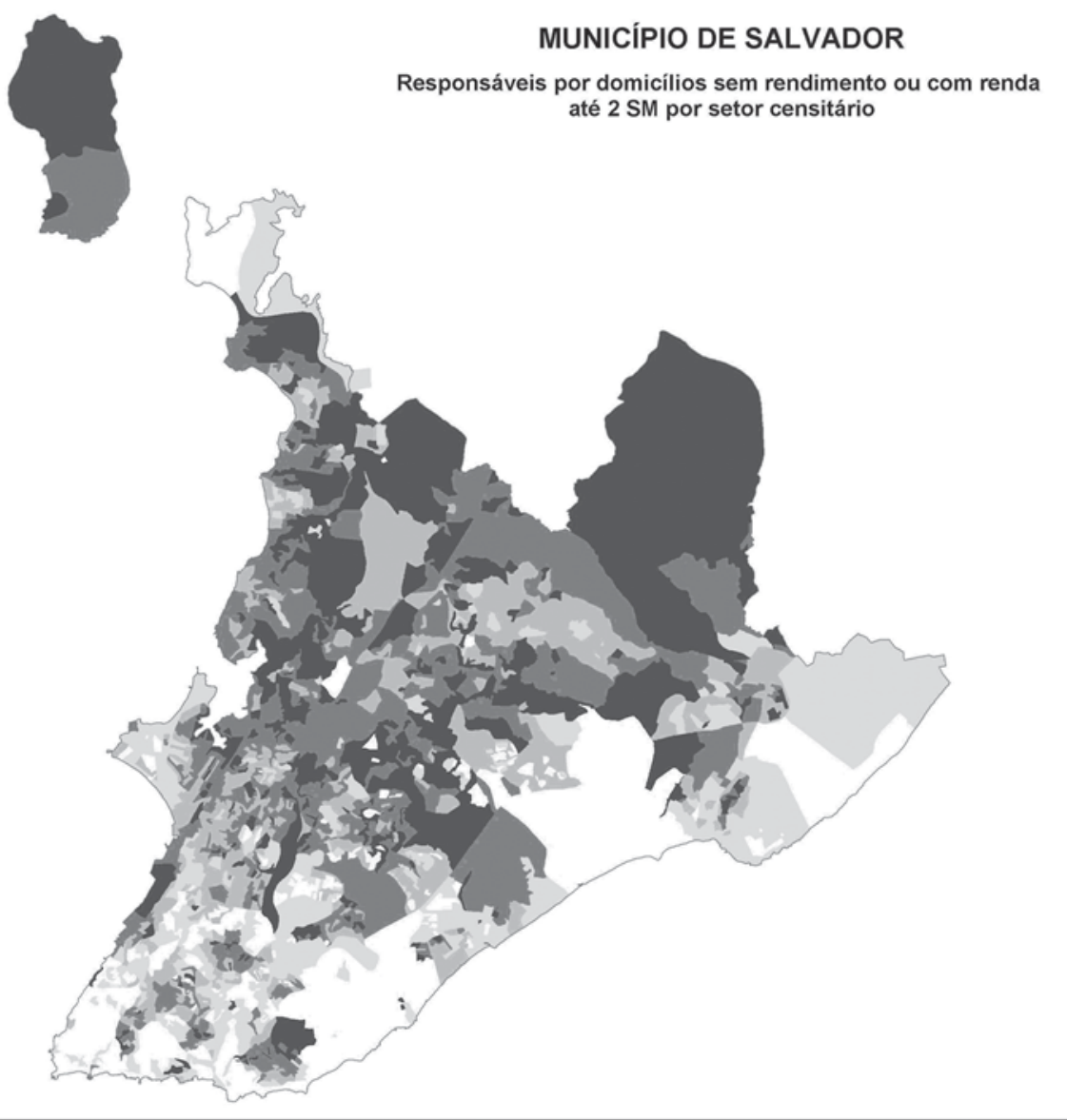

FIGURA 4 - MUNICÍPIO DE SALVADOR, RESPONSÁVEIS POR DOMICÍLIOS SEM RENDIMENTO OU COM RENDA ATÉ 2 SM POR SETOR CENSITÁRIO 


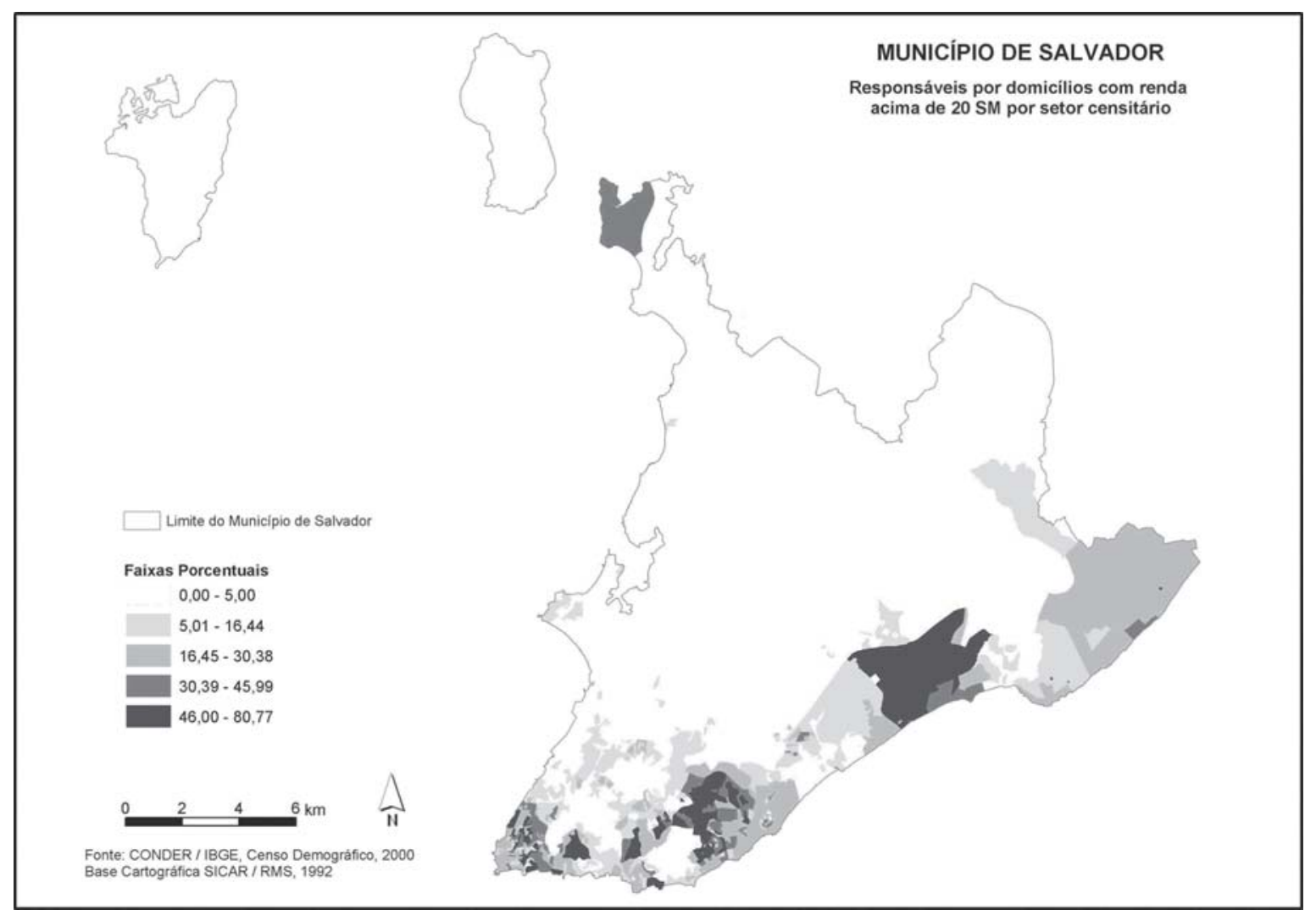

FIGURA 5 - MUNICÍPIO DE SALVADOR, RESPONSÁVEIS POR DOMICÍLIOS COM RENDA ACIMA DE 20 SM POR SETOR CENSITÁRIO

SALVADOR: VALOR MÉDIO DOS TERRENOS EM USS/M² POR REGIÕES ADMINISTRATIVAS - 1996

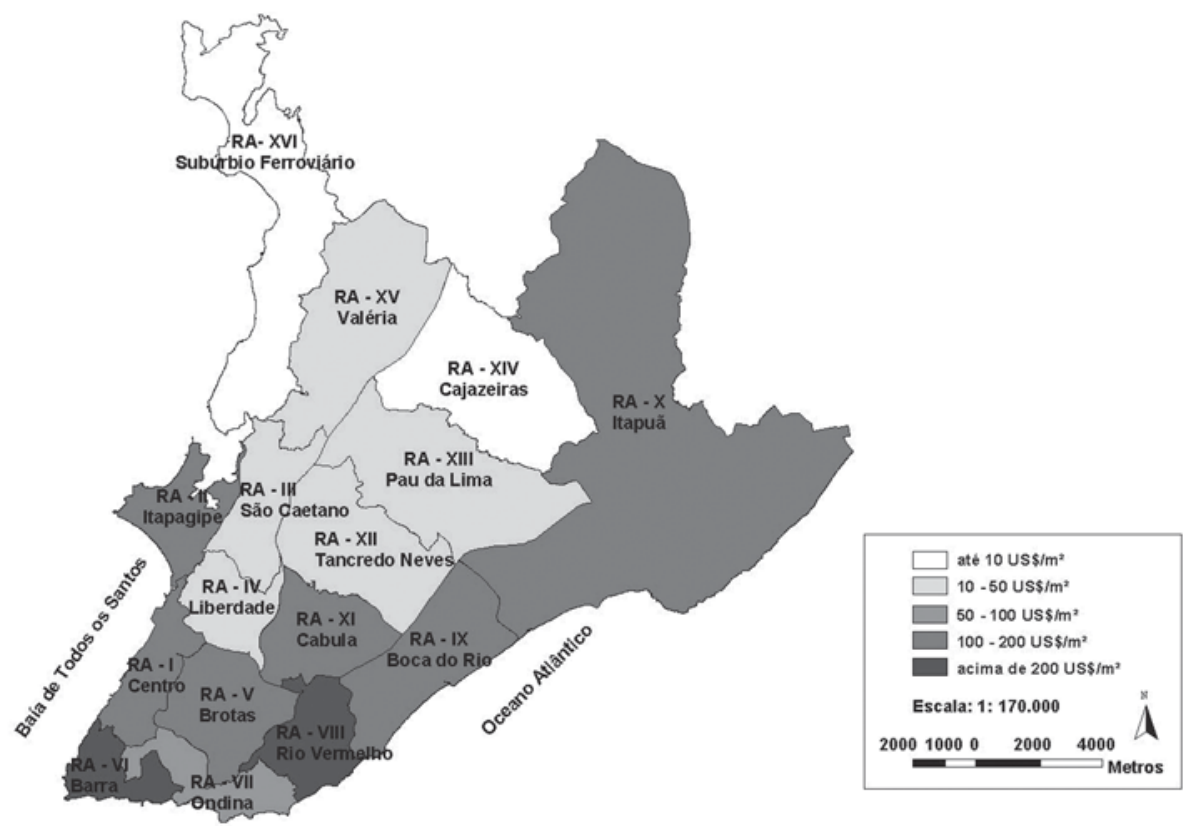

Fonte: Elaborado por Cristóvào Brito; com base em classificados do Jornal A Tarde do ano de 1996. Reelaborado por Ana Rosa Iberti e Angelo Serpa.

FIGURA 6 - VALOR MÉDIO DOS TERRENOS EM US\$ POR REGIÕES ADMINISTRATIVAS EM SALVADOR - BAHIA 
SERPA, A. Gestão territorial do sistema de parques públicos em...

TABELA 1 - DISTRIBUIÇÃO DE PARQUES, PRAÇAS E LARGOS POR REGIÃO ADMINISTRATIVA SALVADOR - NOVEMBRO DE 2000

\begin{tabular}{|c|c|c|c|c|c|}
\hline $\mathbf{R A}$ & $\begin{array}{l}\text { População } \\
\mathbf{N}^{0} \text { de Hab. }\end{array}$ & $\begin{array}{l}\text { Parques } \\
\text { Unid./m² }\end{array}$ & $\begin{array}{c}\text { Praças } \\
\text { Unid./m }\end{array}$ & $\begin{array}{c}\text { Largos } \\
\text { Unid./m }\end{array}$ & $\begin{array}{l}\text { Área Total } \\
\left(\mathrm{m}^{2}\right)\end{array}$ \\
\hline I - Centro & 80.174 & $1 / 110.000$ & $\begin{array}{c}39 / \\
130.701,14\end{array}$ & $23 / 39.546,91$ & $280.248,05$ \\
\hline II - Itapagipe & 146.736 & - & $\begin{array}{c}25 / \\
42.805,84\end{array}$ & $13 / 50.143,10$ & $92.948,94$ \\
\hline III - S. Caetano & 207.914 & - & $6 / 3.400,80$ & $3 / 782,57$ & $4.183,37$ \\
\hline IV - Liberdade & 176.757 & - & $13 / 2.029,20$ & $4 / 8.088,50$ & $10.117,70$ \\
\hline V - Brotas & 185.550 & - & $6 / 5.468,11$ & $3 / 1.469,53$ & $6.937,64$ \\
\hline VI - Barra & 66.143 & $1 / 250.000$ & $5 / 8.464,30$ & $5 / 1.583,20$ & $260.047,50$ \\
\hline VII - R. Vermelho & 167.809 & - & $\begin{array}{c}15 / \\
32.533,64\end{array}$ & $7 / 13.712,35$ & $46.245,99$ \\
\hline VIII - Pituba & 73.819 & $2 / 800.000$ & $\begin{array}{c}17 / \\
72.755,20\end{array}$ & - & $872.755,20$ \\
\hline IX - Boca do Rio & 100.610 & $\begin{array}{c}3 / \\
4.657 .600\end{array}$ & $9 / 16.802,27$ & - & $4.674 .402,27$ \\
\hline X - Itapuã & 176.776 & $\begin{array}{c}2 / \\
2.550 .000\end{array}$ & $\begin{array}{c}17 / \\
122.598,88\end{array}$ & $4 / 12.557,70$ & $2.685 .156,58$ \\
\hline XI - Cabula & 130.122 & - & $2 / 1.424,80$ & $2 / 1.591,10$ & $3.015,90$ \\
\hline XII - Tancredo Neves & 178.803 & - & $5 / 5.778,00$ & - & $5.778,00$ \\
\hline XIII - Pau da Lima & 179.639 & - & $10 / 8.927,40$ & - & $8.927,40$ \\
\hline XIV - Cajazeiras & 124.922 & - & $1 / 4.180,00$ & $1 / 366,30$ & $4.546,30$ \\
\hline XV - Valéria & 61.909 & $1 / 750.000$ & - & $1 / 1.025,00$ & $751.025,00$ \\
\hline XVI - Subúrbio Ferroviário & 241.741 & - & $6 / 8.816,80$ & $2 / 315,00$ & $9.131,80$ \\
\hline XVII - Ilhas & 2.287 & $2 / 340.000$ & - & - & 340.000 \\
\hline Total & 2.301 .711 & $\begin{array}{c}12 / \\
9.457 .600\end{array}$ & $\begin{array}{c}176 / \\
466.686,38\end{array}$ & 68/ 131.181,26 & $10.055 .467,64$ \\
\hline
\end{tabular}

FONTE: ESTUDO DE LAZER - PDDUA SALVADOR, 2002.

Parques que passaram por processos recentes de reabilitação urbana como os de Pituaçu ou da Cidade encontram-se imediatamente próximos aos bairros considerados "nobres".

Assim, fica evidente que projetos, programas e intervenções recentes foram realizados em função de estratégias de valorização do solo urbano, em bairros com maior concentração de população de melhor poder aquisitivo (Figura 6). Essas estratégias baseiam-se em um modelo ideal de cidade, onde a criação de espaços públicos, o "embelezamento urbano", entre outros, constituem estratégias de marketing urbano, de acordo com o paradigma de Barcelona. As opções de desenho urbano adotadas e a estética desses espaços reforçam seu caráter mercadológico. A observação in loco atesta a adoção de um partido a um só tempo estético e comercial. O parque confere "identidade" ao espaço urbano, é uma "imagem" a ser exibida e consumida como qualquer outra mercadoria.

A estratégia de promoção de uma imagem positiva de Salvador por meio da revalorização de seus espaços públicos faz parte do receituário do planejamento estratégico, importado de Barcelona pelas últimas gestões municipais. A cidade catalã tornou-se uma referência para o mundo, pela capacidade de atrair um evento de porte como os Jogos Olímpicos de 1992, o que contribuiu para a elaboração e implantação de seu plano estratégico. Esse modelo aposta na criação de holdings, consórcios ou empresas mistas para executar ações de desenvolvimento urbano. Tanto a requalificação como a adoção de espaços públicos por empresas privadas segue a lógica da visibilidade e da expectativa de retorno por meio da propaganda e do marketing.

O problema é que esses programas não atendem, via de regra, as áreas periféricas da cidade, onde o abandono de parques e praças é notório. É este exatamente o caso do Parque de São Bartolomeu, localizado no Subúrbio Ferroviário, um remanescente de mata atlântica que abriga a nascente do Rio do Cobre, considerado espaço sagrado para os praticantes do Candomblé (SERPA, 1996; 1998). O estado de abandono, os assaltos freqüentes, o descaso e a ausência de políticas públicas para o parque inviabilizam os ritos do Candomblé, afastando seus praticantes do local. 
FOTO 1 - PARQUE DE PITUAÇU, SALVADOR-BAHIA

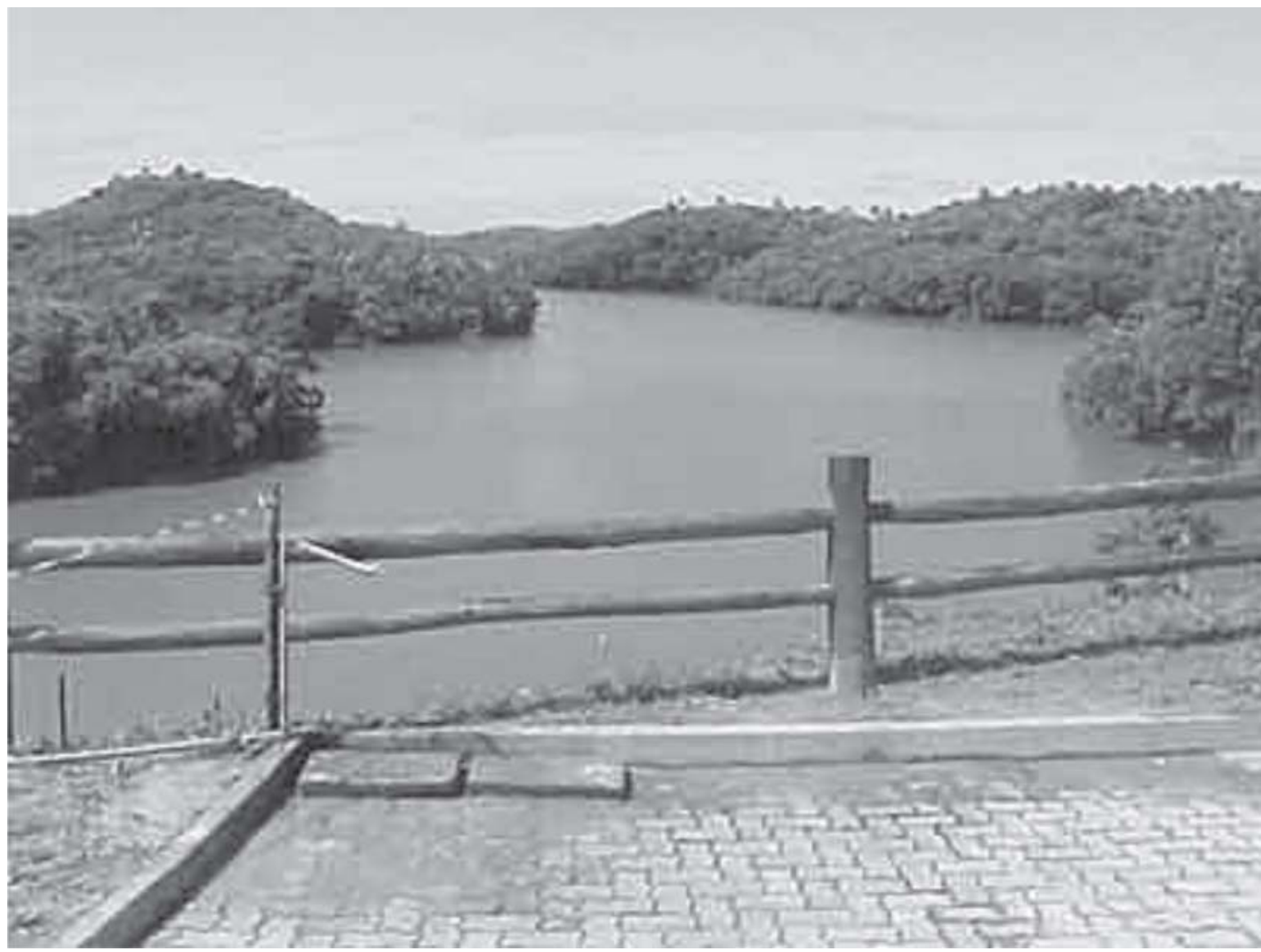

FONTE: WWW.CONDER.BA.GOV.BR/PARQUE_PITUACU.HTM

\section{UM EXEMPLO: O PARQUE DE PITUAÇU, LUGAR DE CONTRADIÇÕES E CLIVAGENS SOCIAIS}

Criado pelo Decreto Estadual n. 23.666, de 4 de setembro de 1973, o Parque Metropolitano de Pituaçu reúne, em seus 450 hectares, uma exuberante vegetação nativa, remanescente de mata atlântica, associada com manguezais, restingas e brejos. O parque reproduz em sua extensão as contradições entre áreas visíveis e menos visíveis, o que pode ser constatado por aqueles que se aventuram pelos 18 quilômetros de sua ciclovia, margeando a lagoa existente. Para além da bonita e bem cuidada entrada principal, pode-se constatar a poluição em vários trechos do espelho d'água, proveniente da Favela do Bate-Facho, vizinha ao parque - uma densa vegetação aquática encobre milhares de metros quadrados do que um dia foi água limpa. Apesar desse grave problema, o parque abriga uma surpreendente biodiversidade, privilégio de poucas áreas urbanas de Salvador: 26 espécies de mamíferos, 113 de aves, 52 de répteis, três de anfíbios e seis de antrópodes (JORNAL A TARDE, 8/2/1998).

O parque é aberto às 6 horas da manhã para quem vem usufruir de sua infra-estrutura de lazer, que inclui uma ciclovia, um bicicletário e um lago com pedalinhos. Os atrativos incluem ainda bares e quiosques com comida e bebidas, playgrounds infantis, além do Espaço Mario Cravo, aberto à visitação, com esculturas do conhecido artista baiano. Além dos problemas de poluição e de degradação das áreas protegidas, a insegurança é motivo de queixa dos usuários. Partes inteiras do parque são tidas como "inseguras" e "perigosas", o que inviabiliza seu uso. Como no Parque da Cidade, o uso restringe-se às áreas com mais equipamentos, no caso do Parque de Pituaçu, toda a área voltada para o mar, distante das áreas vizinhas à Favela do Bate-Facho.

Na Favela não há estrutura de saneamento e drenagem, nem posto policial. $O$ acesso a essa localidade se dá pela Avenida Jorge Amado, fazendo com que o trecho permaneça praticamente isolado do restante do bairro de Pituaçu. Ao longo da Avenida Pinto de Aguiar, também vizinha ao parque, o cenário é bem diferente. É lá onde se localizam o campus da Universidade Católica, assim como o conhecido "trecho dos motéis". A pista é também caminho para o Estádio de Pituaçu e para um dos maiores hotéis das redondezas, o Bahia Sol Atlântico, além de prédios residenciais com bom padrão 


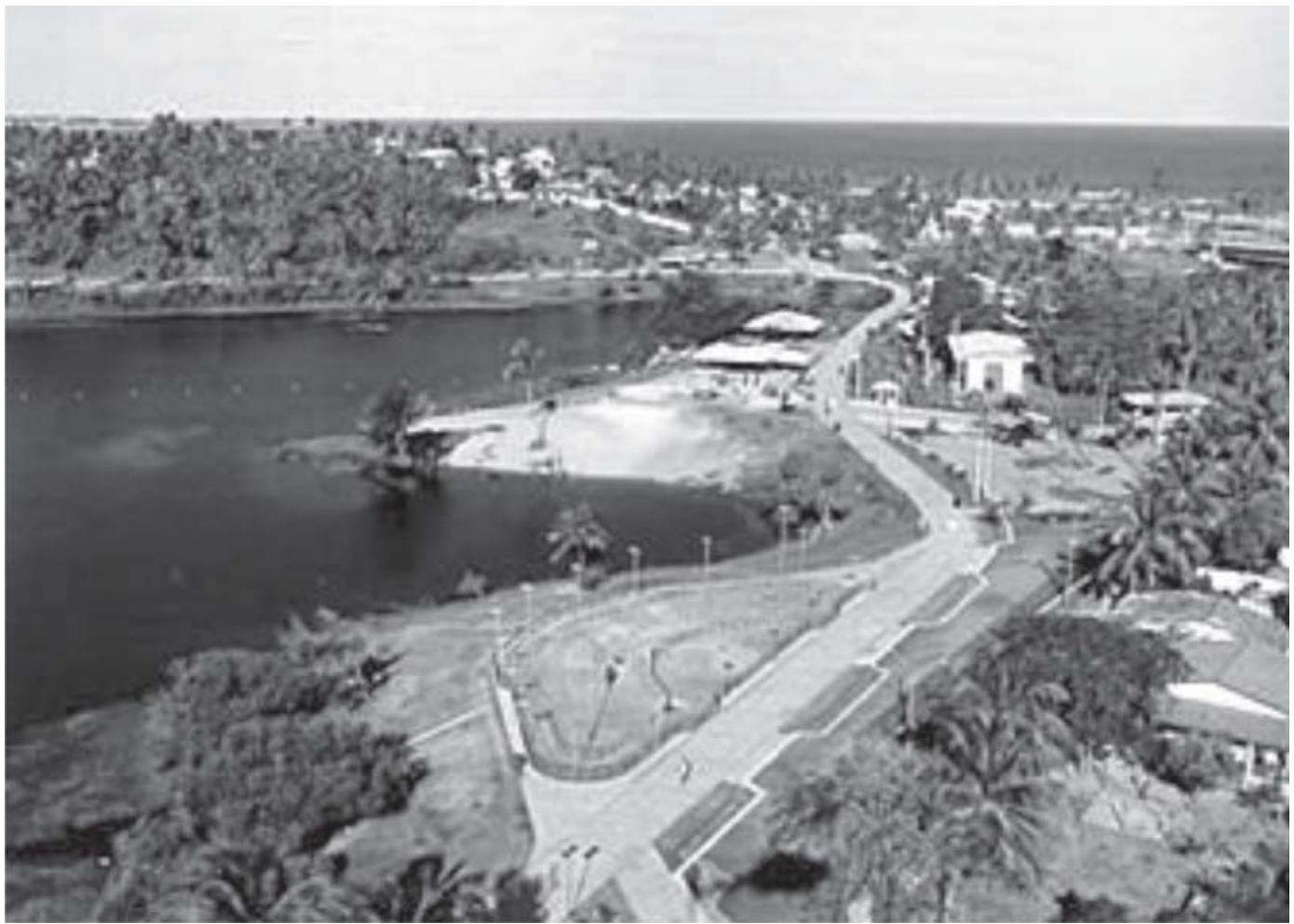

FONTE: WWW.CONDER.BA.GOV.BR/PARQUE_PITUACU.HTM

FOTO 3 - FAVELA DO BATE-FACHO, SALVADOR-BAHIA

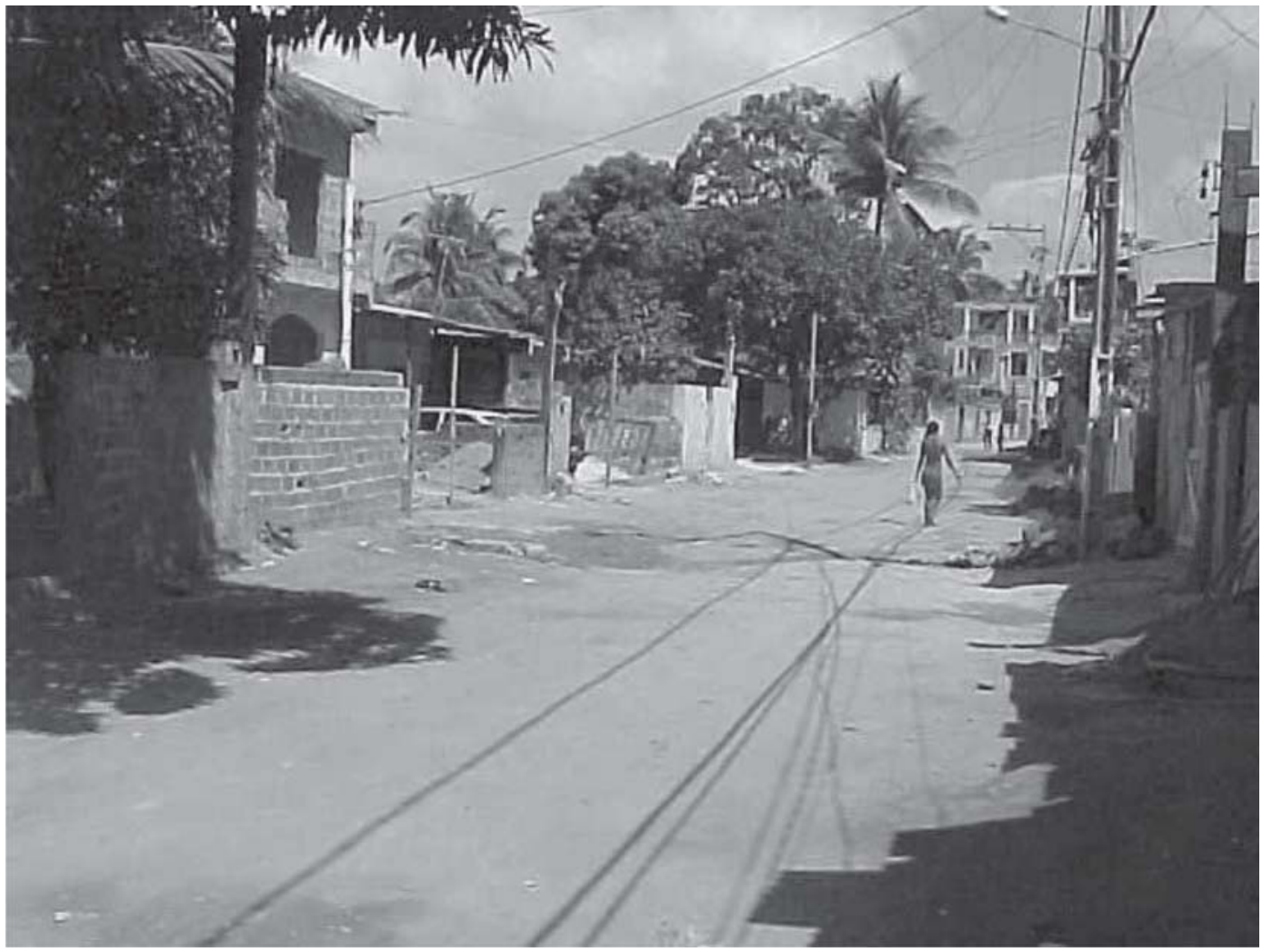

FONTE: HTTP://WWW.CONDER.BA.GOV.BR/TRABALHANDO1.HTM 


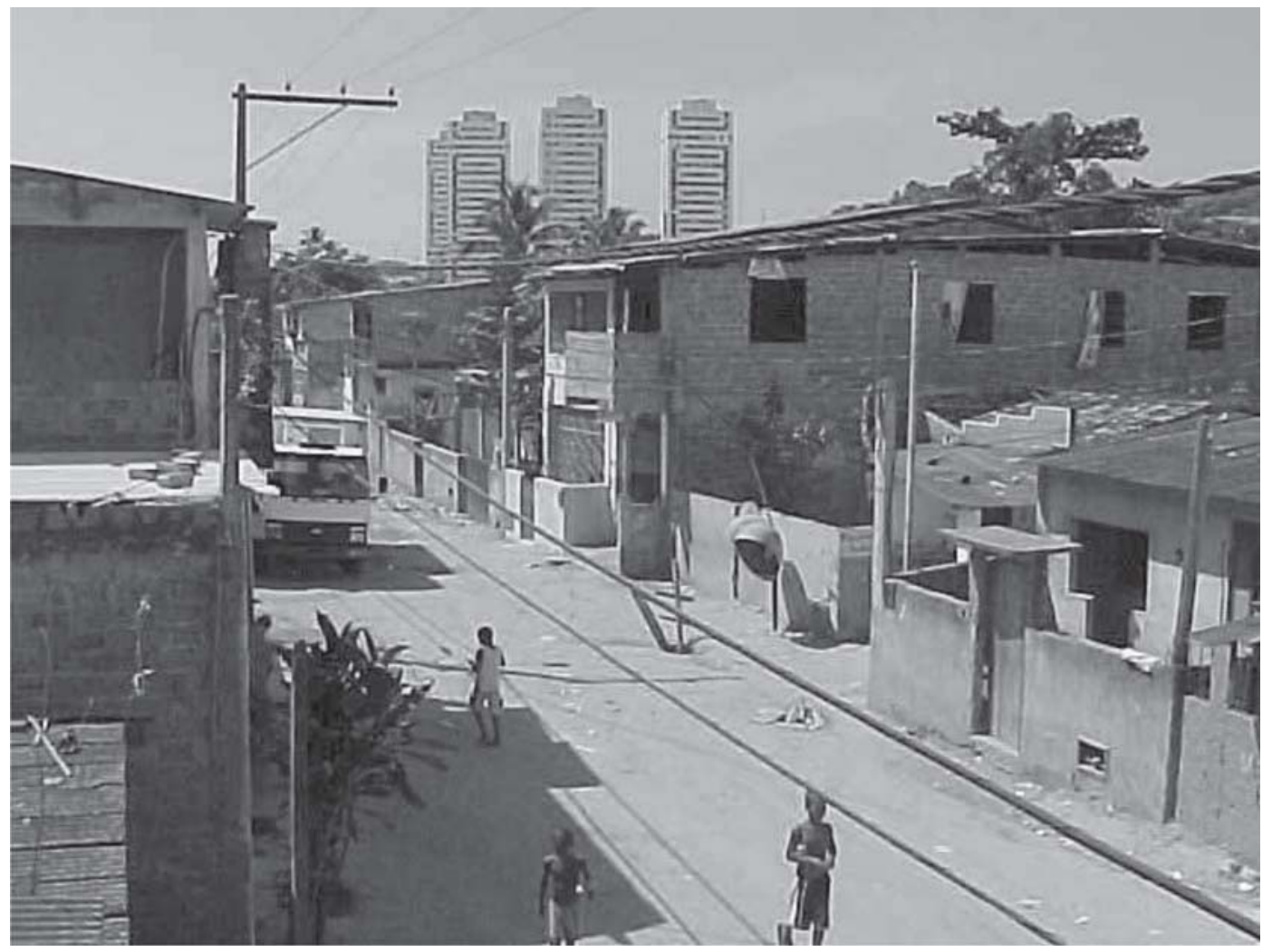

FONTE: HTTP://WWW.CONDER.BA.GOV.BR/TRABALHANDO1.HTM

construtivo e bares que se tornaram pontos de encontro para jovens de classe média (JORNAL A TARDE, 12/1/2002).

No interior do parque, essas clivagens sociais acabam por ser reproduzidas por meio do uso e da apropriação dos espaços, circunscritos às áreas mais visíveis e mais "seguras", de acordo com a percepção dos próprios usuários. Como em outros parques da cidade, o uso durante a semana é menos intenso, restringindose aos estudantes das escolas vizinhas e aos moradores dos bairros próximos. A proximidade de áreas como a Favela do Bate-Facho garante um uso mais "popular" dos equipamentos gratuitos, inclusive nos finais de semana, quando a área atrai moradores de bairros mais distantes, que, em geral, vêm de automóvel e usufruem também dos lazeres "pagos", como o aluguel de bicicletas e pedalinhos e o consumo de bebidas e lanches nos bares e quiosques existentes no local.

\section{À GUISA DE CONCLUSÃO}

A análise dos exemplos ao longo deste artigo mostra que, embora os parques públicos sejam abor- dados tanto sob a ótica ambiental como sob a ótica do lazer no Plano Diretor de Desenvolvimento Urbano e Ambiental, prevalece a última lógica como diretriz das políticas de requalificação urbana desses equipamentos nos limites do território municipal. A lógica da requalificação dos parques e espaços públicos de Salvador não é, portanto, determinada por estratégias baseadas no discurso da "sustentabilidade" ou do "desenvolvimento sustentável", mas sim, e sobretudo, na lógica da valorização do solo urbano e da ampliação do consumo e das alternativas de lazer para um público específico, com maior poder aquisitivo e capital escolar.

Os exemplos analisados mostram também que os parques públicos constituem-se em "bens oligárquicos", na acepção utilizada por Gonçalves (2001), "um bem que só existe se for para poucos". Tendo em vista a pouca disponibilidade de recursos para a gestão e conservação dos parques públicos no território municipal, privilegiam-se aqueles espaços localizados em áreas com boa infra-estrutura de comércio e serviços e que possam exercer a função de atrativos turísticos da cidade. Mas estamos aqui diante de uma contradição, já que uma sociedade fundada na produção de bens oligárquicos é uma sociedade insustentável. Sustentabili- 
dade ambiental pressupõe eqüidade social (compare: GONÇALVES, 2001). O que está em jogo aqui é o paradoxo entre a multiplicação do consumo (desigual) ou o estímulo ao consumismo desenfreado, os parques públicos servindo a esse fim como verdadeiros shoppings a céu aberto, e a idéia mesma de "desenvolvimento sustentável", cuja cientificidade é cada vez mais difícil de sustentar:

A idéia de desenvolvimento sustentável é uma idéia diluidora, entre outras coisas, porque tem origem num campo do agir humano cuja natureza é produzir consensos. Sabemos que a idéia de desenvolvimento sustentável não surgiu em nenhuma área acadêmica, nem em nenhuma área científica. É uma idéia que surgiu no campo diplomático. Foi no interior da Comissão Brundtland da ONU que essa idéia ganhou, por assim dizer, cidadania, como uma idéia que agradaria a todo mundo e, portanto, não diria o que precisava ser dito. Aliás, sublinhe-se, é da natureza do campo diplomático buscar os consensos, até porque o diplomata é aquele cuja função é evitar a guerra (GONÇALVES, 2001, p. 143). Como o famoso e infundado índice de "metros quadrados de áreas verdes por habitante", cuja origem deve-se muito provavelmente a um "boato ecológico"4 (compare: YÁZIGI, 1994), erramos ao considerar científicos conceitos, índices e variáveis que não possuem legitimidade acadêmica. No caso do índice de áreas verdes por habitante, um morador de um bairro popular da cidade, como o Curuzu $^{5}$, deve se perguntar, com justa razão, onde estão, afinal, seus "metros quadrados" de verde. Esse índice, além de não possuir fundamentação teórica e empírica, diz pouco, muito pouco, sobre as verdadeiras raízes do problema, assim como o conceito de "sustentabilidade". Sustentabilidade para quem? Metros quadrados de áreas verdes para quem? A questão da acessibilidade e da distribuição espacial dos espaços públicos de natureza deve ser o cerne de uma discussão acadêmica profunda, que possa fundamentar em outras bases a gestão dos parques públicos no território municipal.

\section{REFERÊNCIAS}

EMELIANOFF, C. Les villes européennes face au développement durable: une floraison d'initiatives sur fond de désengagement politique. Cahiers du PROSES, n. 8, Sciences-Po, 2004.

GONÇALVES, C. W. P. Meio ambiente, ciência e poder. In: SORRENTINO, M. Ambientalismo e participação na contemporaneidade. São Paulo: Educ/Fapesp, 2001. p. 135161.

JORNAL A TARDE. Salvador, 8 fev. 1998; 12 jan. 2002.

PLANO DIRETOR DE DESENVOLVIMENTO URBANO DE SALVADOR. Estudos ambientais - relatório final. Salvador: Seplam/ PMS, 2004.
PLANO diretor será discutido em cinco audiências. Correio da Bahia, Salvador, 01 out. de 2006, p. 17.

SERPA, A. Ponto convergente de utopias e culturas: o Parque de São Bartolomeu. Revista Tempo Social, São Paulo, v. 8, n. 2, p. 177-190, 1996.

SERPA, A. Fatores socioculturais na avaliação de impactos ambientais: o caso da periferia de Salvador. Cadernos do Expogeo, Salvador, v. 9, n. 9, p. 23-33, 1998.

YÁZIGI, E. O ambientalismo: ação e cientificidade em dúvida. Revista do Departamento de Geografia, São Paulo, n. 8, p. 85-96, 1994.

\footnotetext{
4 "No Brasil se repete muito que a ONU estabelece para os centros urbanos, um mínimo de $16 \mathrm{~m} 2$ de áreas verdes por habitante; já ouvimos o índice de $12 \mathrm{~m} 2$ apenas. Em colóquios com funcionários da ONU, ouvimos que até então a ONU jamais estabelecera este patamar, que talvez tenha sido a opinião pessoal de alguém da ONU que visitou o Brasil há duas décadas..." (YÁZIGI, 1994, p. 89-90).

${ }^{5}$ O Curuzu possui uma população afro-descendente de baixa renda e sofre com muitos problemas de infra-estrutura urbana. Localiza-se na Região Administrativa IV (Liberdade), a RA com menos metros quadrados de área verde da cidade.
} 